www.periodicos.unimontes.br/index.php/caminhosdahistoria

\title{
TERRORISMO DE GÊNERO: ESTRATÉGIA ÀS VIOLÊNCIAS EPISTÊMICAS A PARTIR DE UM DEBATE DECOLONIAL GLOBAL
}

\author{
Ana Paula Jardim Martins Afonso ${ }^{1}$
}

Recebido em: 19/04/2020

Aprovado em: 12/06/2020

\begin{abstract}
Resumo: O presente artigo objetiva apresentar alguns apontamentos iniciais da noção "terrorismo de gênero" e ação "terrorista", como possibilidade de abordagem crítica e teórica às investidas colonialistas de produção de narrativas e violências epistêmicas, a partir do campo da História Global, feminismos subalternos e decoloniais. A hipótese que defendo aqui é de que a partir do que consideramos como "abordagens concorrentes" na História Global, segundo Sebastian Conrad (2019), ou seja, a crítica pós-colonial, os feminismos subalternos e os estudos decoloniais constroem opções epistêmicas plurais desde o sul global em detrimento de uma historiografia hegemônica do Norte. Além disso, apresentar uma possibilidade teórico-metodológica diversa, anticolonial e que abra caminhos para a ruptura dos epistemicídios, ou seja, a invisibilidade, apagamento e destruição de saberes locais. O artigo se divide em duas sessões: na primeira apresentamos o estado da arte do debate em História Global e os estudos subalternos, incluindo os feminismos que se inclinam a esta perspectiva. $\mathrm{Na}$ segunda sessão, refletimos, a partir da breve revisão bibliográfica, como o campo possibilita perceber e compreender a relevância da ação das terroristas de gênero no tempo presente.
\end{abstract}

Palavras-chave: História global; feminismos subalternos; estudos pós-coloniais; terrorismo de gênero.

\section{TERRORISMO DE GÉNERO: ESTRATEGIA PARA LAS VIOLENCIAS EPISTEMICAS DE UN DEBATE GLOBAL DECOLONIAL}

Resumen: Este artículo tiene como objetivo presentar algunas notas iniciales de la noción "terrorismo de género" y acción "terrorista", como una posibilidad de un enfoque crítico y teórico de los ataques colonialistas en la producción de narrativas y violencia epistémica, desde el campo de la historia global, los feminismos. subordinado y decolonial. La hipótesis que defiendo aquí es que, a partir de lo que consideramos como "enfoques competitivos" en la Historia Global, según Sebastian Conrad (2019), es decir, la crítica poscolonial, los feminismos subordinados y los estudios descoloniales han construido opciones epistémicas plurales desde el sur global a expensas de una historiografía hegemónica del norte. Además, presentar una posibilidad teórica y metodológica que es diversa, anticolonial y abre el camino para la ruptura de los epistemicidas, es decir, la invisibilidad, el borrado y la destrucción del conocimiento local. El artículo está dividido en dos secciones: en la primera presentamos el estado del arte del debate en Historia Global y los estudios subordinados, incluidos los feminismos que se inclinan por esta perspectiva. En la segunda sesión, reflejamos, a partir de

\footnotetext{
${ }^{1}$ Doutorandx em História Global pela Universidade Federal de Santa Catarina (UFSC). Membrx do Laboratório de Estudos de Gênero e História (LEGH-UFSC). Colunista do Jornal Balaiada. Mestre e Licenciadx em História pelo Universidade Estadual de Montes Claros (Unimontes). E-mail: paula_jardim@hotmail.com. ORCID: https://orcid.org/0000-0001-7767-6285.
} 
la breve revisión bibliográfica, cómo el campo hace posible percibir y comprender la relevancia de la acción de los terroristas de género en el momento actual.

Palabras clave: historia global; feminismos subordinados; estudios poscoloniales; terrorismo de género.

\title{
GENDER TERRORISM: STRATEGY FOR EPISTEMIC VIOLENCES FROM A GLOBAL DECOLONIAL DEBATE
}

\begin{abstract}
This article aims to present some initial notes of the notion "gender terrorism" and "terrorist" action, as a possibility of a critical and theoretical approach to colonialist attacks on the production of narratives and epistemic violence, from the field of Global History, subordinate feminisms and decolonial. The hypothesis that I defend here is that from what we consider as "competing approaches" in Global History, according to Sebastian Conrad (2019), that is, post-colonial criticism, subordinate feminisms and decolonial studies have built plural epistemic options since the global south at the expense of a hegemonic historiography of the North. In addition, to present a theoretical and methodological possibility that is diverse, anticolonial and opens the way for the rupture of epistemicides, that is, the invisibility, erasure and destruction of local knowledge. The article is divided into two sections: in the first one we present the state of the art of the debate in Global History and the subordinate studies, including feminisms that are inclined to this perspective. In the second session, we reflect, from the brief bibliographic review, how the field makes it possible to perceive and understand the relevance of the action of gender terrorists at the present time.
\end{abstract}

Keywords: Global history; subalterns feminism ; post-colonial studies; gender terrorism.

\section{Introdução}

As tradições historiográficas, a partir do século $\mathrm{XX}$, pautadas nas perspectivas eurocentradas e nos discursos hegemônicos do sujeito moderno-eurocentrado-brancocolonizador-homem (cis), têm sido cada vez mais problematizadas e tensionadas, sejam pelos movimentos feministas do norte (Europa, Estados Unidos da América) e sul global, sejam pelos segmentos menos tradicionais da historiografia. Gostaria de com isso dizer que, as teorias sociais que se apresentam ao final do século XX e início do XXI, sobretudo os movimentos de descolonização em África e Ásia, têm buscado desvencilhar ou romper radicalmente a noção europeia de marcos temporais, que ainda mantém uma lógica colonialista; a partir da categoria de François Hartog (2013) "regimes de historicidade", localizamos o modo como a organização narrativa ocidental apagou quaisquer outras possibilidades de organização coletiva.

A queda do muro de Berlim, do fim da Guerra Fria e a queda da União Soviética, que até então orientavam a direção das narrativas construídas sobre os sujeitos na história, tornamse símbolos organizadores da história do mundo e que nos orientam para o porvir. Consideramos fortemente aqui o argumento de que "estruturas e horizontes de tempo representam um- senão o- ponto de conexão entre a perspectiva de atores e sistema" (ROSA, 
2019, p.9). Por isso, é flagrante que as memórias históricas incessantemente construídas foram arquitetadas para legitimar a dimensão colonizadora e hegemônica da Europa em relação a outras partes do mundo. É fundamental a compreensão da ideia de que a aceleração temporal nos direciona na análise dos processos de globalização no ocidente e seus efeitos de modo global, portanto interconectado e incisivamente colonial/dominador. Mesmo assim, a ideia de aceleração do tempo também possibilitou o surgimento de novas formas de registrar os acontecimentos, de contar histórias, de compreender as reconfigurações das condições de vida.

O efeito discursivo do aparecimento de novas formas de registro e leitura da realidade é, portanto, a fabricação de novas narrativas históricas, reescrita e revisão de narrativas já existentes, além da produção de disputas discursivas cada vez mais acirradas por controle e hegemonia, a fim dominar o campo dos saberes que pleiteiam responder a essas demandas sociais, culturais, políticas e econômicas, portanto históricas. Conforme Hartog (2013), o atual regime de historicidade é marcado por crises acerca do lugar e o papel da história e um apelo ao entrecruzamento e interconexão de saberes.

Nesse sentido, a empreitada teórica da História Global, bem como os feminismos subalternos e estudos pós-coloniais e decoloniais tem apresentado, desde os anos de 1980, uma variedade de possibilidades teórico-metodológicas para o ofício dos historiadores/as. Nesse artigo, consideramos que o campo da História Global nos permite tatear "abordagens concorrentes", como destaca Conrad (2019), de forma conectada, cruzada, transnacional, comparada, subalterna, decolonial; portanto, global. Compreendemos esse campo como um desdobramento narrativo que nos permite questionar epistemologicamente a centralidade e hegemonia da Europa na produção dos saberes históricos, e, conforme destaca Luciana Ballestrin (2013), quando da leitura do conceito de "colonialidade do poder" de Anibal Quijano (2005), apontar a violência epistêmica do esquema colonial/imperial nas produções latino-americanas.

A partir da clássica questão de Gayatri Spivak (2010), "pode um subalterno falar?“" compreendemos que a proposta de uma possível história global se dá por meio de desmistificar o norte global como único produtor e difusor de saberes no globo. Consideramos aqui a possibilidade de vozes subalternas serem ouvidas e produzirem sentido para reduzir os danos dos epistemicídios seculares. Por isso, o presente artigo objetiva apresentar o território de emergência do que chamaremos aqui de "terrorismo de gênero" e ação política das "terroristas de gênero" a partir do breve debate acerca do campo da História Global, feminismos subalternos e decoloniais, como possibilidade de abordagem teórica 
contemporânea e crítica às investidas colonialistas de produção de narrativas e violências epistêmicas.

A hipótese que defendo aqui é de que a partir do que consideramos como "abordagens concorrentes" na História Global, segundo Sebastian Conrad (2019), ou seja, a crítica póscolonial, os feminismos subalternos e os estudos decoloniais, é possível construir uma crítica às bases de uma historiografia hegemônica do Norte, bem como apresentar uma possibilidade teórico-metodológico diversa, anticolonial e que abra caminhos para a ruptura dos epistemicídios, ou seja, a invisibilidade, apagamento e destruição de saberes locais.

$\mathrm{O}$ artigo se divide em duas sessões: na primeira apresentamos o estado da arte do debate em História Global e os estudos subalternos, incluindo os feminismos que se inclinam a esta perspectiva. Na segunda sessão, refletimos, a partir da breve revisão bibliográfica, como o campo possibilita perceber e compreender a relevância da ação das terroristas de gênero no tempo presente.

\section{História Global em perspectiva: abordagens concorrentes no presente}

Em entrevista $^{2}$ ao jornal português "Fumaça" Linn da Quebrada, que se autointitulada como "terrorista de gênero," responde à indagação feita pelo apresentador de modo a nos incitar a reflexão para o debate aqui proposto:

Pedro Miguel: As primeiras palavras que se ouvem no Bixa Travesty são: $\mathrm{Eu}$ quebrei a costela de adão. Muito prazer, eu sou a nova Eva. Filha das travas, obra das trevas. O que é ser esta nova Eva?

Linn: Olha, eu acho que é ser presente, no sentido de estar no presente. Conseguir falar sobre o presente, conseguir ser atravessada por todos esses vetores do que está acontecendo hoje e de pensar estrategicamente mesmo, assim... fazer legião, de formar exércitos. Ser a nova Eva é pra mim ressignificar todo o contexto histórico há tanto tempo escrito por homens de tantas outras gerações falando sobre nós. E a nova Eva, ao invés de ser objeto de estudo, do que os homens escreveram sobre, a Eva é quem toma essa caneta e quem escreve a própria história. Seria a nova versão do evangelho, segundo Eva talvez (DA QUEBRADA, 2018).

A compreensão do "estar no presente" e os vetores que atravessam os sujeitos de que fala Linn pode ser traduzida também na estrutura social que se configura por meio de opressões cruzadas e interconectadas, incidindo sobre esse território de colonização que são

\footnotetext{
${ }^{2}$ A entrevista realizada pela coluna editorial do jornal português "Fumaça" não se apresenta aqui como fonte para pesquisa/debate encampado pelo artigo, mas como estratégia discursivo-literária para iniciar as elaborações acerca da possibilidade de ruptura com vício da "Colonialidade do poder/saber", conforme afirma Anibal Quijano em atravessar e subjugar as vozes dissidentes. Cf. Disponível em < https://fumaca.pt/linn-da-quebradamulheridade-brasil-hoje-resistencia-forca/> Acesso em 16/10/2018
} 
os corpos subalternizados, a partir da categoria "interseccionalidade" (CRENSHAW, 2002). A partir disso é possível organizar narrativas para recontar novas versões dessa história. Portanto, mais do que "dar voz ao subalterno", mas pensar formas de composição de pensamento com estes sujeitos, seguiremos a ideia apresentada de "tomar a caneta e escrever a própria história" (DA QUEBRADA, 2018). Ainda, “mesmo uma história egoísta precisa reconhecer a existência do Outro" (SUBRAHMANYAM, 2017, p.223).

Nesse sentido, se desdobra em questão: o campo da história global nos permite, no limite, considerar o terrorismo de gênero como estratégia contra as violências epistêmicas da historiografia tradicional? Indicamos em um primeiro movimento para compreensão dos/as leitores/as alguns argumentos para vislumbrar o terreno que pretendemos tatear, quais sejam: primeiro ponto considerado é de que a expressão "estar no presente" de que fala Linn da Quebrada, como esse instante sempre atual é o que François Hartog (2013) chama de "regime de historicidade presentista" ou "presentismo".

A percepção que se abre ao horizonte é que o ideal de progresso em direção a um futuro melhor foram colocados em xeque, sobretudo pelo mal-estar gerado pelas guerras mundiais; as contestações de 1968; o avanço da sociedade de consumo; o solapamento das identidades nacionais; o fortalecimento da globalização enquanto o processo de compressão do espaço-tempo nesse presente estendido, dilatado e difuso, por vezes desproporcional. Portanto, o fim do socialismo real em 1989, marco simbólico para François Hartog, uma vez que os regimes de historicidade do leste vendiam a promessa do futuro comunismo "real", mesmo justificando com isso o sacrifício do presente, produzindo assimetrias entre os sujeitos históricos: opressões políticas, violências de raça, gênero, etnia, sexualidade, corpos, classe, entre outros.

O presente, por isso, tornou-se o seu próprio horizonte, num afastamento cada vez maior entre espaço de experiência e horizonte de expectativa, conforme nos apontou Reinhard Koselleck (2006). Ligado a esse argumento, a hipótese acerca da aceleração temporal de Hartmut Rosa (2019) age de modo a complementar a ideia de uma "dilatação temporal no presente".

\footnotetext{
A modernização não é apenas um processo multifacetado no tempo, mas também, primeiramente e, sobretudo, uma transformação estrutural e cultural extremamente importante das próprias estruturas e horizontes temporais, e de que o conceito de aceleração social é o mais apropriado para abranger as direções dessa transformação (ROSA, 2019, p.8).
}

Além de a ideia de aceleração social pressupor a transformação estrutural e cultural, portanto material, pressupõe também uma transformação epistemológica, compreendida a 
partir das "abordagens concorrentes"; por isso, os paradigmas que entram em confluência para constituir uma perspectiva global "partilham um interesse geral em transcender as perspectivas estritamente nacionais e em ir mais além da hegemonia interpretativa ocidental" (CONRAD, 2019, p.54). No limite, faz-se fundamental apresentar a globalização como fenômeno propulsor da dinâmica do entrecruzamento e aceleração do tempo, que nos ajuda a pensar outras possibilidades de escrita da história.

A globalização, processo que assim sintetizado caracteriza-se pelo crescimento da intercomunicação entre sujeitos e lugares e que ocorre em escala global, conecta comunidades e organizações sociais em novos arranjos de espaço-tempo. Nesse sentido, argumenta Stuart Hall (2002) que esse processo nos afasta da noção tradicional de sociedade enquanto um sistema delimitado e coloca-nos frente a uma nova forma de organização e desenvolvimento sociais. Contudo, há que se considerar que a humanidade já se expandia e se interconectava mundialmente ainda no século XVI e então, (...) não há dúvidas de que o fato objetivo central na virada do século XVI foi a integração gradual da América com a Eurásia e com a África. Sabe-se que tal acontecimento teve consequências graves para a população ameríndia, mas tratou-se, no entanto, de uma etapa essencial na transição para uma real "consciência de globalidade" (SUBRAHMANYAM, 2017, p. 233).

Desse modo, as identidades nacionais tem sofrido um processo de fragmentação; as identidades locais têm sido reforçadas pela resistência à globalização; por fim, com a ruína das identidades nacionais, o grande bloco uno/total abre espaço para a constituição de identidades híbridas, conforme aponta Stuart Hall. Dito isso, o autor nos indica em seu argumento importante elemento para reflexão das perspectivas, características e abordagens da História Global.

O que é importante para nosso argumento quanto ao impacto da globalização é que o espaço e o tempo são também coordenadas básicas de todo sistema de representação. Todo meio de representação - escrita, pintura, desenho, fotografia, simbolização através da arte ou dos sistemas de telecomunicação - deve traduzir seu objeto em dimensões espaciais e temporais. [...] Diferentes épocas e culturas têm diferentes formas de combinar essas coordenadas espaço-tempo. [...] Podemos ver novas relações de espaçotempo sendo definidas em eventos tão diferentes [...] (HALL, 2002, p.70).

A fala de François Hartog acerca das experiências de tempo, com destaque para um fragmento acerca da globalização e seus impactos, nos motiva pensar em que medida este acontecimento/processo nos apresenta terreno fértil para a consolidação História Global.

Para além dos elogios ou das denúncias da globalização, os observadores não deixaram de destacar o avanço - de mãos dadas - do global e do local, da uniformização e da diferenciação. Tanto mais o global parece vencer, 
mais ele trabalha em profundidade os ritmos e os modos de vida, mais, aqui e ali, a preocupação com as diferenças tende a se afirmar e procurar ser reconhecida. Daí, em particular, o investimento e as mobilizações múltiplas em diferentes lugares dessas palavras-chave dos anos 1980 que são memória (com o dever de memória), identidade (com suas buscas e demandas de reconhecimento) e patrimônio (sob a forma, notadamente, do "patrimônio universal da humanidade", promovido pela UNESCO) (HARTOG, 2013a, p. 165).

$\mathrm{Na}$ esteira dos processos de encurtamento de distâncias, assistimos aos processos de descolonização afro-asiáticos que, sobretudo nos anos de 1960/1970, trouxeram às paisagens ocidentais novas configurações e cores de outros lugares no mundo, sobretudo em África e Ásia; ao passo também que foram fundamentais para o surgimento de novas narrativas para compor o repertório das historiografias nacionais. Então, essa "aceleração do tempo histórico" nos reorientou a encontrar novas formas de escrita da história, capazes de compreender de que maneira surgiram e se apresentam essas novas condições de vida, bastante distintas das formas de escrita que tinham maior expressão na historiografia em fins dos anos de $1989 .^{3}$

Posto desse modo, conforme Rosa (2019), o tempo torna-se uma problemática que incita pensar nossa perspectiva de vida como um todo, que se fragmenta, se rearranja, se dispõe de diversas formas. O estar no tempo que se reconfigura é, no limite, acelerado e o que se procura, portanto, é acomodar as micro-experiências dispersas e localizadas em narrativas que se entrelaçam, que dão sentido e historicidade ao movimento-devir-humano.

Nesse mote, a esse cenário de aceleração e mudanças tão rápidas, “a natureza coletiva dos modelos temporais concretos resulta especialmente na necessidade de sincronização" ou seja "(re) temporalização do tempo, que requer análise cultural e estrutural” (ROSA, 2019, p.21). Por isso, o argumento que defendo é que a partir do campo da história global, dos feminismos subalternos e decoloniais é possível dar sentido ao caos espaço-temporal. Ou seja, os feminismos subalternos e decoloniais, por meio de um diálogo concorrente dentro do campo da história global, podem ser mobilizados e combinados de modo a re-temporalizar o tempo. Em outras palavras, podem ser chamados a reestabelecer as relações entre passado, presente e futuro, orientando a experiência do tempo em virtude das expectativas de espaços (e corpos) plurais do Sul Global.

O termo História Global é relativamente emergente. Conforme Conrad (2019),

A história global nasceu da conviç̧ão que os instrumentos analíticos utilizados pelos historiadores para estudar o passado já não eram suficientemente adequados. A globalização lançou um desafio fundamental às ciências sociais e às narrativas dominantes sobre a mudança social, $\mathrm{O}$

\footnotetext{
${ }^{3}$ Importante destacar que este ano foi, em muitas das narrativas históricas, um marco para acontecimentos que nos direcionaram para o que muitos teóricos apontaram como o "fim da história”. Cf. FUKUYAMA, 1992.
} 
momento atual, que emergiu de sistemas de interação e troca, é caracterizado por redes e entrelaçamentos. No entanto, em muitos aspetos, as atuais ciências sociais não são capazes de colocar as perguntas certas e de gerar respostas que expliquem a realidade das redes e do mundo globalizado (CONRAD, 2019, 13).

É possível dizer que longe de se definir, tal perspectiva ou atitude historiográfica ainda se mantem como um campo em alta tensão e abordagens concorrentes. Então, muito do que se produziu em termos do que se pode localizar como história global é antes objeto de problemáticas classificações e agrupamentos.

A história global procura enfrentar os desafios colocados por estas observações e ultrapassar aquelas duas infelizes «marcas de nascença» das disciplinas modernas. Embora se debruce sobre um conjunto de temáticas como a migração, o colonialismo ou o comércio —, que há muito são objetos de estudo dos historiadores, a história global apresenta uma abordagem revisionista (CONRAD, 2019, p.14).

A uma perspectiva global é possível atribuir o desejo de reestruturar o terreno que se consolidou a historiografia dos séculos XIX e XX, na tentativa de romper com abordagens compartimentadas, em específico com a abordagem de uma história nacional (CONRAD, 2019). Por isso, ao horizonte de expectativa escatológico do fim da história, os historiadores/as fizeram desnudar o modo como parte significativa da produção historiográfica da época ajudava a produzir e reproduzir um ideal de superioridade civilizacional contidas nas teorias da cultura ocidental sobre os sujeitos, os espaços e o tempo. Então, na medida em que aparecem tais narrativas comprometidas em responder às mudanças, Por isso, seria urgente deslocar o Estado-Nação como principal eixo de análise dos acontecimentos históricos.

Vejamos que, conforme nos apresenta Santos e Sochaczewski (2017), há certa dificuldade em deslocar esse eixo analítico, uma vez que a constituição da disciplina histórica, na segunda metade do século XIX, remonta ao surgimento dos Estados Modernos e juntamente a isso, a criação de institutos de preservação e registro de memória da história nacional, documentos produzidos pelo e para o Estado. Então, a referência que constitui as bases da disciplina, por si só, tem como marcos essas instituições que dão prioridade a documentação produzida nesses espaços e que, por sua vez, priorizam narrativas eurocêntricas que desconsideraram por muito tempo a produção de outros centros e outras localidades.

Nesse sentido, reestruturar as bases disciplinares da história, significa nas palavras de Conrad (2019)

Por um lado, assinala a indiscutível posicionalidade de qualquer interpretação do passado - a não ser que queiramos reduzir a história a uma única narrativa, precisamos ter em conta a multiplicidade das mesmas. Por 
outro lado, uma forte ênfase na particularidade e na singularidade pode facilmente produzir afirmações de incomensurabilidade, ou seja, a defesa de que os recursos culturais subjacentes às diferentes sociedades são tão radicalmente distintos entre si, que torna mas sociedade mutuamente incompreensíveis (CONRAD, 2019, p.198).

Importante salientar que mesmo com a proposta de ampliar e conectar estes blocos geográficos, essa tendência não se fez de maneira homogênea. Há uma variedade de subabordagens, como a história comparada, a história cisatlântica, circum-atlântica e a transatlântica (ARMITAGE, 2014, p. 209), o que Conrad subdivide e destaca como abordagens concorrentes ${ }^{4}$.

Ainda que essa tendência tivesse repercutido como alternativa a superação de eurocentrismos, é importante salientar que para alguns historiadores só é possível falar em história atlântica nos recortes entre 1492 e a 1872 e nesse sentido, posteriormente é mais interessante falar em história global. Um dos nomes que aparece como resposta às críticas é Immanuel Wallerstein. A ideia de "sistema mundo" proposta pelo teórico entende que a ideia de um Estado soberano ou uma sociedade nacional não deve ser a unidade de análise que norteia uma pesquisa em história. Para ele, somente um sistema social poderia explicar a mudança social em sistemas sociais e um único sistema explicativo não daria conta dessa análise mais sistêmica.

Até agora, vimos alternativas e propostas advindas do norte global e que falam acerca de tendências do norte global. Nesse sentindo, ainda não operamos um deslocamento mais profundo nas tendências historiográficas apresentadas como tentativas de solucionar a tensão entre lugares relegados à a-historicidade. Por isso, é fundamental apresentarmos aqui produções que vêm de centros não ocidentais para marcar a disputa pelo campo discursivo de domínio da história.

Os "Estudos subalternos", surgidos na Índia na década de 1980 foi influenciado pelas contribuições da perspectiva marxista inglesa. Contudo, não se compreende como simples conformação da "história vista de baixo" a uma realidade local, mas pensa as singularidades políticas, sociais e culturais da Índia que pressionaram a historiografia "subalterna" a fim de propor uma reinvenção teórico-metodológica que escapasse às tendências eurocentradas. Dessa maneira, buscaram sair em defesa de maior cruzamento histórico, destacando vantagens a partir dessas conexões. Além disso, priorizaram a capacidade de estabelecer relações entre objetos, análises, fontes e metodologias e meios para institucionalizar essas produções, com a criação de revistas e periódicos para divulgação.

\footnotetext{
${ }^{4}$ Cf.: CONRAD, 2019, p. 53-75.
} 
Por fim, a pluralidade de estratégias apresentadas tem como ponto de encontro escapar da redução das análises históricas a um só eixo de unidade, eurocentrado e ocidental, evitando o aprisionamento e a limitação dos objetos de pesquisa a narrativas nacionalistas e deslocar as relações de poder do eixo do Norte Global. Portanto, ainda há muito caminho a ser percorrido pela história e historiografia, o que não deixa de ser interessante para pesquisa, uma vez que esse campo que se constitui como histórico é tão dinâmico e vivo como a própria vida e, desse modo, necessita estar em trânsito constante de reinvenção.

\title{
Terrorismo de gênero, vozes da subalternidade e o giro decolonial
}

É fundamental, antes de tudo, que reconheçamos os sujeitos que ocupam espaços de poder e de privilégios. Dito isso, tomaremos às mãos a caneta de Clio para (re)escrever uma narrativa de resistência para as vozes de feminilidade, racialidade, sexualidade, corporalidade e subjetividade que as relações do poder colonial tratam de precarizar e minar suas potências. Estabelecendo as dimensões de subalternidade, pensaremos a partir da crítica decolonial de que modo é possível fazer do espaço destas linhas ruptura às violências epistêmicas que emudecem vozes outras.

Quem é Mc Linn da Quebrada? Nas palavras dela: "Bicha, trans, preta e periférica. Nem ator, nem atriz, atroz. Bailarinx, performer e terrorista de gênero.” Por isso, tomamos de empréstimo o termo "terrorista de gênero" a fim de pensar que é no corpo e na própria existência que começa o enfrentamento das minorias políticas. Por isso, Ballestrin nos alude que:

\begin{abstract}
As relações e intersecções entre feminismo e pós-colonialismo são muitas, podendo se dar de outras e diferentes maneiras. Apesar de ambas correntes de pensamento possuírem uma trajetória autônoma e uma vocação transdisciplinar, as críticas feminista e pós-colonial compartilham de características e preocupações constitutivas dos movimentos históricos que as estruturam (...): tanto os movimentos feministas quanto os anticoloniais precisaram questionar as ideias dominantes de história e representação, uma vez que a cultura é vista como um campo de conflito entre opressores e oprimidos, no qual a linguagem pode ser uma ferramenta de dominação. Para ambos, a problematização do sujeito ocidental homem e branco nos discursos imperialistas europeus é um ponto de partida fundamental (BALLESTRIN, 2013, p.137).
\end{abstract}

Justamente para pensar as reconfigurações do tempo histórico, a emergência de novos problemas, demandas sociais, políticas, culturais e econômicas, é fortuito estabelecermos as considerações acerca do sul global, desde voz de uma artista periférica do sul global. Conforme Ballestrin, adotaremos a “opção decolonial” - epistêmica, teórica e política - para 
compreender e atuar no mundo, marcado pela permanência da colonialidade global nos diferentes níveis da vida pessoal e coletiva" (BALLESTRIN, 2013, p.89).

Nesse mote, a opção epistêmica pelo decolonial se faz aqui, para a partir de uma abordagem concorrente no campo da história global, abrir caminhos que rumam a romper com as relações colonialistas que ainda permanecem, sobretudo, no que tange às formas como se produzem narrativas sobre esse outro colonizado, bem como a hegemonia eurocêntrica e ocidental. "Nós existimos, somos seres atuantes dentro do nosso cenário político e social, contribuímos de forma efetiva e relevante com nossas produções. E só me pergunto por que demorou tanto tempo para que isso acontecesse ${ }^{5 "}$ (DA QUEBRADA, 2020).

Conforme indicado por Conrad no fim da sessão anterior, uma das abordagens concorrentes dentro da história global são os "estudos pós-coloniais". Por isso, conforme nos apresenta Inocência Mata (2014)

(...) os destinadores das teorias pós-coloniais pretendem que elas funcionem, também, como instrumento de análise de relações de hegemonia e desvelamento da colonialidade do saber segundo uma estratégia de resistência a sistemas de conformação da tendência hierarquizante da diferença, como seja, por exemplo, o eurocentrismo (MATA, 2014, p.31).

Partindo do argumento de que o mundo moderno se constitui com base numa ordem colonial, que no limite, opera na lógica da exploração e dominação, construção do Outro como território passível de dominação, faremos o esforço de caminhar para radicalização do argumento, conforme aponta Luciana Ballestrin (2013) e pensar a possibilidade de um "giro decolonial". Deflagrado o giro decolonial é possível perceber e compreender a relevância da ação das terroristas de gênero no tempo presente.

Por isso, descolonizar o pensamento se fez imprescindível, uma vez que é necessário que possamos nos munir de armas estratégicas nas táticas de guerrilhas urbanas ideológicas do contexto político no Brasil contemporâneo. O que o conceito de colonialidade do poder traz de novo é a leitura da raça e do racismo como "o princípio organizador que estrutura todas as múltiplas hierarquias do sistema-mundo" (GROSFOGUEL, 2008, p. 123). Conforme diz Houria Bouteldja (2016), é necessário pensar o sujeito com o maior denominador comum de opressões para que seja possível travar uma batalha mais justa. Linn da Quebrada, terrorista de gênero, cria estratégias políticas em tempos sombrios de censura, repressão e recrudescimento de valores morais.

\footnotetext{
${ }^{5}$ Conferir entrevista na íntegra, disponível em: <https://www.huffpostbrasil.com/entry/linn-da-quebrada-bixa-

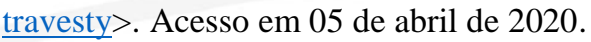


A criação de novas estratégias, de uma ação terrorista que desestabiliza a relação colonial, é fundamental pensar de que modos podemos rearranjar o dilema das identidades, que por muito foram elos que aprisionaram na lógica da dominação colonial este Outro que o ocidente quis aniquilar. Acerca da questão das identidades, é fundamental as perspectivas críticas à unidade do sujeito moderno, sobretudo o que dizem Stuart Hall e Tania Navarro Swain. Para pensar acerca do conceito de identidade, Stuart Hall nos diz que,

A questão da identidade está sendo extensamente discutida na teoria social. Em essência, o argumento é o seguinte: as velhas identidades, que por tanto tempo estabilizaram o mundo social, estão em declínio, fazendo surgir novas identidades e fragmentando o indivíduo moderno, até aqui visto como um sujeito unificado. A assim chamada "crise de identidade" é vista como parte de um processo mais amplo de mudança, que está deslocando as estruturas e processos centrais das sociedades modernas e abalando os quadros de referência que davam aos indivíduos uma ancoragem estável no mundo social (HALL, 2002, p. 7).

Corrobora o argumento Swain corrobora o argumento quando diz que "a necessidade de delimitar um espaço em que se reivindique uma identidade, baseada em diferentes posições de sujeito, faz com que esta categoria seja alçada a uma condição da existência, de possibilidade de ser e de atuar no mundo." (SWAIN, 2000, p.12). Portanto, pensar a identidade e o sujeito como construtos sociais, como processos em curso, ao longo da vivência humana, traz-nos a perspectiva de uma identidade fluida, transitória e múltipla, que significa apenas o que já fui e não sou mais. Mais uma vez, Swain advoga que “(...) uma cartografia identitária é, afinal, o que nos resta para observarmos o percurso de opções, movimentos e atuações ao longo de nossas histórias pessoais/sociais.” (SWAIN, 2000, p.14).

É, precisamente nesse ponto, que à vida é negado o movimento, tornando-a assim, passível de ser apropriada. Conforme Guacira Louro, “(...) os sujeitos vêm sendo indicados, classificados, ordenados, hierarquizados e definidos pela aparência de seus corpos; a partir de padrões e referências, das normas, valores e ideais da cultura" (LOURO, 2015, p.77). Por isso, as forças que nos tencionam se valem das dicotomias: natural/antinatural, bom/mau, puro/impuro, normal/patológico, para apagar tudo aquilo que é diferente, novo, vivo e histórico.

Então, ao pensarmos nessas linhas que nos unem é fundamental destacar que a natureza, assim como a identidade, são situações ilusórias, como formas de aprisionar o sujeito dentro de um espaço delimitado, construído a partir de normas socialmente prescritas, fixando-os cada vez mais nesse invólucro. Pretendemos, antes de tudo, enquanto um trabalho em história, produzir um tipo de conhecimento que contribua para romper e desconstruir o 
modo como as teorias feministas articulam seus modelos explicativos do mundo através dos conceitos de gênero, propondo modos alternativos que problematizem os rearranjos dessas relações entre o corpo, sexo e gênero.

As "terroristas de gênero" criam espaços nas relações cotidianas, desmontam o amontoado de coisas que os silenciam, e que regulam o modo de vida que constituem para si. Esses modos de vida extrapolam as fronteiras, e expõem com maior clareza os mecanismos que os capturam. É nesse sentido, que Preciado sentencia: "sabemos que seu aparelho de produção de verdade já não funciona mais" (PRECIADO, 2013, s.p). "As terroristas de gênero" dão pane nesses aparelhos de produção, e mostram exatamente onde se localizam os defeitos desse maquinário do poder. Nesse sentido, a ideia de uma ação terrorista aqui é compreendida na medida em que denunciam "a continuidade das formas coloniais de dominação após o fim das administrações coloniais, produzidas pelas culturas coloniais e pelas estruturas do sistema-mundo capitalista moderno/colonial" (GROSFOGUEL, 2008, p.126)

Linn da Quebrada, Danny Bond, Lia Clark, Glória Groove, Rosa Luz, Drika Barbosa, Caio Prado, Verônica Decide Morrer, Lineker, Liniker e os Caramelows, Jaloo, Pablo Vittar são algumas das vozes que se levantam para questionar a validade das noções identitárias segmentadas. Estas vozes compõem a dissonância sinfônica do funk que vem da periferia, e segundo Preciado (2013),

Eles dizem representação. Nós dizemos experimentação. Eles dizem identidade. Nós dizemos multidão. Eles dizem domesticar a periferia. Nós dizemos mestiçar a cidade. Eles dizem dívida. Nós dizemos cooperação sexual e interdependência somática. Eles dizem capital humano. Nós dizemos aliança multi-espécies. Eles dizem carne de cavalo nos nossos pratos. Nós dizemos "montemos nos cavalos para escaparmos juntos do abatedouro global". Eles dizem poder. Nós dizemos potência (PRECIADO, 2013, s.p).

Linn da Quebrada diz que: "Terrorista de gênero significa ter a minha música como uma arma apontada para minha própria cabeça". O terrorismo foi uma das estratégias usadas nas guerrilhas urbanas em 1968 para incidir sobre o "terror" legitimado pelo estado hegemônico (pelos militares). Se o termo foi amplamente criminalizado pelo Estado, aqui é considerado arma de guerra em que a arte é o operador que evidencia as disputas e ações políticas por legitimidade de existência.

\footnotetext{
${ }^{6}$ Chamamos aqui de terroristas de gênero, conceito apropriado da artista Linn da Quebrada, aquelas que são capazes de colocar em movimento o subversivo, arriscar o impensável, fazer balançar as estabilidades e certezas - processos geralmente incômodos às práticas sociais hegemônicas e normativas, além de lançar mão de um arcabouço teórico belicoso na escrita. (LOURO, 2015, p.7. Grifos meus).
} 
Portanto, a ideia de terrorismo que se apresenta aqui cria espaços nas relações cotidianas que denunciam a violência e terror do Estado, e que regulam, com autonomia, o modo de vida que constituem para si. São sujeitos que, por extrapolarem a lógica hegemônica do Estado, expõem com maior evidência os mecanismos que tentam capturar essas vidas desviadas. Linn da Quebrada nos apresenta estratégias políticas por meio do campo da cultura, entendendo que os preconceitos nascem, sobretudo desse campo e sensibilizar outros corpos para chamar sua atenção é uma ação mais efetiva.

Além disso, quando Linn comenta que "produz sua música como arma", opera por meio do artivismo-terrorista, na medida em que entende que as identidades são fluidas e podem ser criadas, recriadas e subvertidas permanentemente. Desorganizar a estrutura formal/colonial do que se compreende como homem/mulher na sociedade é apontar uma arma potente na cabeça desses grupos que tentam conformar essas subjetividades em caixas que já não cabem mais. Por fim, Linn da Quebrada rejeita profundamente a ideia de que para obter respeito ou criar uma imagem "respeitável" as pessoas devem abdicar de suas singularidades que as fazem potentes.

Nesse sentido, pensar uma terrorista de gênero a partir de uma perspectiva decolonial se fez bastante imprescindível, uma vez que é necessário que possamos nos munir de armas estratégicas nas táticas de guerrilhas urbanas ideológicas do contexto político no Brasil contemporâneo. Conforme diz Houria Bouteldja (2015), é necessário pensar o sujeito com o maior denominador comum de opressões para que seja possível travar uma batalha mais justa.

De que modo o terrorismo, dentro de um jogo de consenso e dissenso, opera de modo a flexibilizar a racionalidade da violência cometida pelo Estado, ao mesmo tempo em que possibilita pensarmos tanto as guerrilhas urbanas do contexto de 1968 no Brasil, quanto as Linn da Quebrada, como artivista-terrorista, são capazes, conforme Gramsci, "de criar uma nova forma ético-política”? (GRAMSCI, 1999, p.314-315). Precisamente nessa nova forma ético-política, portanto contra-hegemônica, Linn da Quebrada artivista-terrorista, portanto potente e resistente à lógica de dominação de corpos, gênero e sexualidade.

Para Gramsci, a ideia de hegemonia nos indica a conquista de consenso e monopólio cultural, político-ideológico de um grupo em relação a outros em dada sociedade. Além dos aspectos econômicos, a ideia de hegemonia diz respeito a uma disputa de percepções entre sujeitos de uma ação política. Por isso, diz respeito também à expressão de saberes, práticas, modos de representação e modelos de autoridade que se pretende legitimar e universalizar.

O Estado que garante legitimidade de suas ações, lançando mão da violência, é também e paradoxalmente, aquele que garante a segurança e perpetra o terror generalizado e 
legal contra a sociedade. Ao compreendermos a ideia de biopoder ou poder sobre a vida de Michel Foucault, é possível analisar os investimentos desse Estado de "terror" tendo sobretudo, a sexualidade, como objeto e investimento político. Entendendo a hegemonia de um modo de vida (branco-homem-heterossexual-cis-classe-média-) que é universalizada e naturalizada, incutido de forma a ser largamente produzido e reproduzido, é possível aproximarmos biopolítica, racismo de estado, hegemonia e terrorismo.

Conforme Michel Foucault (1998), quase todo o modus operandi dos Estados modernos passa, em última instância, pelo problema do racismo. O racismo, compreendido na lógica do biopoder, é o modo pelo qual esse mecanismo se incumbiu de operar um corte entre o que deve viver e o que deve morrer. Um modo de afastar, no interior da população, um grupo em relação a outro. Opera na lógica de fragmentar, fazer censuras, ou seja, essa racionalidade legada ao Estado do poder de fazer viver e de deixar morrer. Por isso, corpos como os de Linn da Quebrada entram na lógica do "deixar morrer". Todavia, quando diz que "Ser bicha travesti preta é o que me dá força. Meu corpo é o ponto de partida do meu trabalho", se coloca como esse estado de terror que é ponto fora da curva e que escapa às malhas do biopoder.

Ainda, evocando as palavras de Dorotea Gómez Grijalva, quando diz que "mi cuerpo és um território politico", Linn da Quebrada se vale desse argumento para defender a sua consciência política em relação aos direitos étnicos frente ao Estado e fazer sua denúncia da sociedade que é machista, racista e homofóbica. É no corpo e por meio dele que a artista convoca àqueles que se deixam atravessar pela intensidade de afetos que são compostos com suas performances.

Por isso, é fundamental desapegarmo-nos do ideal de perseguir as origens fundacionais da vida humana, que são tão caras ao nosso campo discursivo. A partir disso, todavia, compor e apreciar o trânsito, investigar as fronteiras deste outro - que a produção de saberes historiográficos do norte global "esqueceu" de mencionar como elemento imprescindível nas lutas, conquistas. Esse Outro, diferente, desviante e desviado, foi transformado em ameaça. Portanto, justifica-se seu silêncio, sua obliteração na narrativa.

O medo dessa sociabilidade com a diferença sempre foi o voto de minerva na escolha destes produtores do saber na história. O outro que recolocamos no protagonismo dos acontecimentos políticos trata-se justamente dessas possibilidades múltiplas que podemos assumir. Sendo assim, de que modo os discursos que vemos circular conseguem produzir, materialmente, corpos, sexualidades, identidades e gêneros que se apresentam como o apêndice da escrita da história? Coloco aqui a historiografia tradicional como o próprio 
discurso de ódio que se constitui, e que se faz hegemônico, ao conseguir produzir materialmente o outro como diferença, mas uma diferença que ameaça, que mata e é passível do aniquilamento.

Assistimos nos últimos anos na sociedade brasileira e no mundo, a uma tentativa evidente de conformar essas multiplicidades das vidas, em uma moral do referente universal. Nesse sentido, Judith Butler (2015) reitera, que a matriz cultural, por meio da qual as identidades se tornam inteligíveis exige que certos tipos de "identidade" não possam existir, na medida em que se entende que é necessária uma coerência entre práticas e materialidade do corpo. Então, essa coerência firma-se sob a égide normativa daquilo que é considerado branco-heterossexual-burguês-homem - se constituindo, pois, por uma relação política de direito instituída pelas leis culturais, que estabelecem e regulam a forma e o significado de uma vida.

Dessa forma, libertar a história e a historiografia da lógica do ressentimento, que fixa modelos e cristaliza sujeitos, e constrói para eles, uma identidade colonialista, criando relações de submissão, regulando as práticas sociais e estabelecendo critérios e níveis destas relações. Por isso, de terrorismo como estratégia potente para resistir às investidas da colonialidade dos corpos e do poder para análise dos acontecimentos históricos contribui, na medida em que viabiliza novas formas de vida, e destrói subjetividades cativas e identitárias.

No contexto atual de conservadorismo no Brasil contemporâneo e de constante precarização da vida, é fundamental a problematização destes modos de vida históricos que escapam ao funcionamento das investidas dos enquadramentos colonialistas que aprisionam e matam e se constituem como potências de vida. As demandas que emergem a partir da ideia já discutida da (re) temporalização do tempo nos permite problematizar sexualidade, gênero, etnia, classe, bem como inúmeros outros marcadores que indicam o entrelaçamento de elementos que constituem os sujeitos do contemporâneo. Gays, lésbicas, transexuais, travestis, crossdressers, dragqueens $e$ drag kings, negros/as, pobres, vidas nuas, vidas precárias compõem o quadro da multidão. Deste modo, faz-se urgente problematizar estas vidas que escapam enquanto objeto para perspectivas contemporâneas da historiografia.

Por isso, a investida do poder colonial sobre essas vidas desviantes serve, justamente para enganá-las de que não há potência, conforme aponta Pál Pelbart:

Coube a Deleuze explicitar que poder sobre a vida deveria responder o poder da vida, a potência "política" da vida na medida em que ela faz variar suas formas e, acrescentaria Gattari, reinventa suas coordenadas de enunciação. De maneira mais ampla e positiva, essa potência da vida no contexto 
contemporâneo equivale precisamente à biopotência da multidão (...) (PÁL PELBART, 2011, p.25).

Quando o sujeito se dá conta da sua potência de vida, inventa então novas crenças, novos desejos, novas composições e novas formas de rearranjo. É nesse ponto, que o poder vai tentar capturar cada vez mais esses sujeitos que se formam sob uma lógica desviante. Diante de tais cenários, os holofotes da historiografia se voltam para a vida, para as subjetividades. Então, compreendemos que os modos de vida que se constituíram enquanto hegemônicos e aqueles que, a partir desta constituição se tornaram o outro, tentam estabelecer uma coexistência que se pauta na eterna disputa pelo exercício de poder.

\section{À baila de conclusão...}

$\mathrm{Na}$ tentativa de apresentar breve debate de perspectivas, tendências e posicionamentos emergentes nas teorias do século XX e XXI, a História Global, os estudos pós-colonais, feminismos subalternos e decoloniais apresentam-se como uma infinidade de caminhos que podemos seguir para apresentar leituras cada vez mais lúcidas da realidade. Seja como for, dispomo-nos de abordagens das mais diversas e o presente artigo tentou versar acerca de alguns pontos interessantes sobre as mais atuais críticas às tradicionais correntes e perspectivas analíticas da história. Importante deixar evidente que, sejam quais forem os caminhos escolhidos, é fundamental que se quebre os grilhões com os nacionalismos metodológicos, bem como se descolonize o pensamento, para fazer valer o que nos ensina Anibal Quijano, além de abandonar também as amarras a que estão presas nossas subjetividades que acabam produzindo narrativas exclusivamente eurocentradas/ocidentais.

Nesse sentido, o campo da História Global tem muito a nos oferecer, apresentando-nos diversificação de temas, objetos e fontes que, é bastante fortuito para contribuir e manter o campo da História dinâmico, equitativo e múltiplo. Assim, é fundamental também retomar as sugestões sobre os cuidados teóricos e metodológicos para as pesquisas, que vão desde os recortes temáticos, temporais e espaciais e escolhas das fontes e o arsenal discursivo escolhido para o combate.

Em nossa sociedade, a norma que se estabelece, historicamente, remete ao homem branco, heterossexual, de classe média urbana e cristão e colonizador; essa passa a ser a referência que não precisa ser nomeada. Serão os "outros" sujeitos sociais que se tornarão "marcados", que se definirão e serão denominados a partir dessa referência. Dessa forma, a mulher é representada como "segundo sexo" e gays e lésbicas são descritos como desviantes 
da norma heterossexual. Distintas e divergentes representações podem circular e produzir efeitos sociais.

Refletir acerca desses novos/as atores que roubam a cena das práticas sociais e políticas e a institucionalização dos saberes, sobretudo os estudos feministas é compreender a importância de manifestação de margens de manobra frente às demandas que surgem desses movimentos de conquistas e existências dessas vidas que antes não entravam de modo legítimo “no jogo político' e nos cálculos do poder. No momento em que se conquista também se abdica de muita coisa.

Destarte, a partir do campo da história global, dos feminismos subalternos e decoloniais é possível dar sentido ao caos espaço-temporal. Ou seja, os feminismos subalternos e decoloniais, por meio de um diálogo concorrente dentro do campo da história global, podem ser mobilizados e combinados de modo a (re) temporalizar a experiência temporal dos sujeitos e romper com sentidos de produção de violências e opressões cruzadas e entrelaçadas. Em outras palavras, podem ser chamadas a reestabelecer as relações entre passado, presente e futuro, orientando a experiência do tempo em virtude das expectativas de espaços (e corpos) plurais do Sul Global.

\section{Referências bibliográficas}

ARMITAGE, David; GULDI, Jo. The History Manifesto. Cambridge, MA: Cambridge University Press, 2014.

BALLESTRIN, Luciana. América Latina e o giro decolonial. Rev. Bras. Ciênc. Polít., Brasília, n. 11, p. 89-117, Ago. 2013.

BALLESTRIN, Luciana. Feminismos Subalternos. Estudos Feministas, Florianópolis, 25(3): 530, setembro-dezembro/2017.

BARROS, José d'Assunção. História comparada. Petrópolis: Vozes, 2014a.

BRAUDEL, Fernand. O Mediterrâneo e o Mundo Mediterrânico na Época de Felipe II. São Paulo: Martins Fontes, 1983 [1949]. 2 v.

BUTLER, Judith. Problemas de gênero: feminismo e subversão da identidade. Rio de Janeiro: Civilização Brasileira, 2015.

CHAKRABARTY, Dipesh. Provincializing Europe: Postcolonial Thought and Historical Difference. Princeton University Press, 2000.

CONRAD, Sebastian. O que é história global?. Nova Jersey: Princeton University Press, 2019.

COSTA, Sergio. Pós-colonialismo e différance. In: COSTA, Sergio. Dois Atlânticos: teoria social, anti-racismo, cosmopolitismo. Belo Horizonte: UFMG, 2006.

CRENSHAW, Kimberlé. Documento para encontro de especialistas em aspectos da discriminação racial relativos ao gênero. Estudos Feministas, vol. 10, n. 1, p. 171-188, 2002. FOUCAULT, Michel. História da sexualidade 1: A vontade de saber. Trad. Rio de Janeiro: Graal, 1998.

GÓMEZ GRIJALVA, Dorotea. Mi cuerpo un territorio político. En: Voces Descolonizadoras. Cuaderno 1. Ed. Brecha Lésbic, 2013. 
GRAMSCI, Antonio. Cadernos do cárcere - Introdução ao Estudo da Filosofia. A Filosofia de Benedetto Croce. Rio de Janeiro: Civilização Brasileira, 1999. 494 p. v. 1.

GROSFOGUEL, Ramón. Para descolonizar os estudos de economia política e os estudos póscoloniais: transmodernidade, pensamento de fronteira e colonialidade global. Revista Crítica de Ciências Sociais, n. 80, 2008. p. 115-147.

HALL, Stuart. A identidade cultural na pós-modernidade. Tradução: Tomaz Tadeu da Silva, Guacira Lopes Louro. $7^{\circ}$ ed. Rio de Janeiro: DP \& A, 2002.

HARTOG, François. Ordens do tempo, regimes de historicidade. In: HARTOG, François. Regimes de historicidade. Belo Horizonte: Autêntica, 2013. p.17-41.

HARTOG, François. Experiência do tempo: da história universal à história global?. História, Histórias, Brasília, v. 1, n. 1, p. 164-179, 2013a.

LOURO, G. L. Um corpo estranho: ensaios sobre sexualidade e teoria queer. 2.Ed.; 2.reimp. Belo Horizonte: Autêntica, 2015.

MATA, INOCÊNCIA. Estudos pós-coloniais: desconstruindo genealogias eurocêntricas. Civitas. v.14, n.1, p. 27-42, 2004.

PELBART, Peter Pál. Vida capital: ensaios de biopolítica. SP: Iluminuras, 2003.

PRECIADO, Beatriz. Manifesto contrassexual: práticas subversivas de identidade sexual. Trad. Maria Paula Gurgel Ribeiro. São Paulo: n-1 edições, 2014.

PRECIADO, Beatriz. Multidões queer: notas para uma política dos "anormais". Revista Estudos Feministas, v. 19, n. 1, p. 11-20, 2011.

PRECIADO, Beatriz. Nós dizemos revolução! Libération, França, 20 de mar 2013. Culture. Disponível em < http://next.liberation.fr/culture/2013/03/20/nous-disons-revolution_890087> acesso em 05/08/2016.

QUIJANO, Aníbal. Colonialidad del poder y clasificación social. Journal Of WorldSystems Research, v. 11, n. 2, 2004, p. 342-386.

ROSA, Hartmut. Aceleração: A transformação das estruturas temporais na Modernidade. São Paulo: Editora Unesp, 2019.

SANTOS, João Júlio Gomes Júnior; SOCHACZEWSKI, Monique. História Global: um empreendimento intelectual em curso. 2017. Revista Tempo. Vol.23 n.3. Set./Dez/ 2017.

SPIVAK, Gayatri Chakravorty. Pode o subalterno falar? 1. ed. Trad. Sandra Regina Goulart Almeida; Marcos Pereira Feitosa; André Pereira. Belo Horizonte: Editora da UFMG, 2010.

SUBRAHMANYAM, Sanjay. Em busca das origens da História Global: Aula inaugural proferida no Collège de France em 28 de novembro de 2013. Estudos Históricos. Rio de Janeiro, Vol. 30, nº 60, p.219-240, 2017.

SWAIN, Tania Navarro. A invenção do corpo feminino ou a hora e a vez do nomadismo identitário. Textos de História: Revista do Programa de Pós-Graduação em História da Unb. Brasília, Unb, vol.8, n.1/2, p. 47-86, 2000.

SWAIN, Tania Navarro. Imagens de gênero em quadrinhos. Universa (UCB), BRASÍLIA, v. 5, n. 3, p. 401-414, 1997. 